\title{
POETRY AND SCIENCE
}

$\mathrm{O}^{\mathrm{s}}$ December 9, the P.E.N. (Poets, Playwrights, Editors, Essayists and Novelists) Club held an informal discussion on poetry and science. The participants were Prof. Herbert Dingle, professor of the history and philosophy of science, University College, London; N. W. Pirie, head of the Biochemistry Department, Rothamsted Experimental Station; G. S. Fraser, a poetic critic ; and Stephen Spender, a well-known poet. The chairman was Kathleen Nott, a poet who has written about the subject under discussion.

At first sight it might appear that these branches of culture had little to do with each other. But Prof. Dingle gave instances of the antagonism between poets and scientists, and pointed out that the overt attacks arising from this antagonism in the past were made by the poets. This, he said, is understandable; at that time it was thought that there was a real external world, the truth about which was being increasingly found out by the scientists. To poets, this world seemed flat and distasteful, but at the back of their minds the uncomfortable thought grew that any alternative was mere illusion. In Prof. Dingle's opinion, however, there is no need for the poet to harbour such resentment. The philosophical background has altered; and with this alteration, the activities of poet and scientist appear compatible. Omar Khayyam compared the first appearance of light out of darkness to a flung stone, and to the noose of a rope. Scientists also have compared light to a moving particle, and to an agitated cord. Finally, they have settled down to an equation embracing both concepts; but it is nonsense to say that light is an equation. In fact, science is the organized description of the relations between experiences; poetry, the expression of the experiences themselves.

This description of the limits of science, abnegatory as it might seem, did not dispel the injured suspicion of the poets present. Stephen Spender, side-stepping Prof. Dingle and attacking Kathleen Nott, re-asserted the right of the individual to subjective knowledge of truth. He said that the psychologist may attribute the cause of conscience to infantile experiences; he himself might attribute it to God; what elaim has science to the unique truth of the matter ? Not only are the findings of science uncomfortable in detail ; they are also so complicated that no one man can understand them, and increase of understanding brings with it disorientation and despair.

G. S. Fraser brought in some second-order corrections to complicate Prof. Dingle's neat separation of the subjects. The findings of science are themselves some of the experiences of the poet. Donne was aware of Copernicus, and this awareness brought on discomfort to which he gave poetic expression. The quality of exactness is not confined to science, for poetry has its own criteria of exactness. A difference between poet and scientist is that whereas one particularizes, the other generalizes.

N. W. Pirie broke down the icy rigidity which science is apt to assume in such discussions, and gave a warm and humorous description of the scientist at work. In a highly selected environment records of observations are made. These statements are no more dramatic in content than 'the cat sat on the mat'. Having puzzled over these statements, and discarded those he dislikes, the scientist begins to devise a theory (which must be generally plausible), and to shape it into a form acceptable for publication. The language of scientific publication, by a long-enforced tradition, is strangulated in the extreme; any poet could be excused for finding it repulsive-though the use of the word 'elegant' is permitted. But, said Mr. Pirie, let us turn from the first and last of these processes to the second; in the act of imaginative creation the poet is not far from the scientist.

Neither in the opening addresses nor in the general discussion did the representatives of science and poetry get to grips. Prof. Dingle renounced certain territorial claims, and thereby lowered the intracultural tension. But he discreetly omitted any reference to one defended area of science : that of attempted approximate consistency. Of course, it is absurd to say that light is identical with an equation. But the equation itself is (in the meaning of the words familiar to scientific men) true of light; and only by changing the frame of reference can we say that it is true of ripeness that 'ripeness is all'. The chorus of approval of Humpty-Dumpty's attitude to words obliterates the fact that his conversation with Alice, like much of this discussion, was inconclusive.

To comfort any class of humans, especially poets, is an amiable end. But the study of poetry from the viewpoints of anthropology, individual psychology or information theory has interested some poets and might increase the knowledge (if not the comfort) of more.

C. E. G. BaILEY

\section{STUDY OF THE BRITISH FLORA DURING 1953}

ADITIONS to the knowledge of the British A flora during 1953 have not included spectacular discoveries of the kind reported in $1951^{1}$ and $1952^{2}$, but the year has been marked by steady progress in many branches of research. The annual exhibition meeting of the Botanical Society of the British Isles, which was arranged in the lecture room of the British Museum (Natural History) on November 28, will be remembered for the close studies of small groups and demonstrations of new techniques rather than for the new species and hybrids to the British list, and extensions of range of previously known plants.

The technique used by P. F. Yeo (University of Cambridge) in his exhibit of wild and cultivated specimens from six populations of Euphrasia nemorosa was of particular interest. $H e$ has overcome the difficulty of growing this partial parasite under satis. factory standard conditions by raising plants in pots which each contained a single plant of Plantago lanceolata to serve as a host. The method might well be adapted for the study of other critical parasitic 